\title{
USGS Research on Atlantic Coral Reef Ecosystems
}

\section{Overview}

Coral reefs are massive, biomineralized structures that protect coastal communities by acting as barriers to hazards such as hurricanes and tsunamis. They provide sand for beaches through the natural process of erosion, support tourism and recreational industries, and provide essential habitat for fisheries. The continuing global degradation of coral reef ecosystems is well documented (for example, fig. 1). There is a need for focused, coordinated science to understand the complex physical and biological processes and interactions that are impacting the condition of coral reefs and their ability to respond to a changing environment.
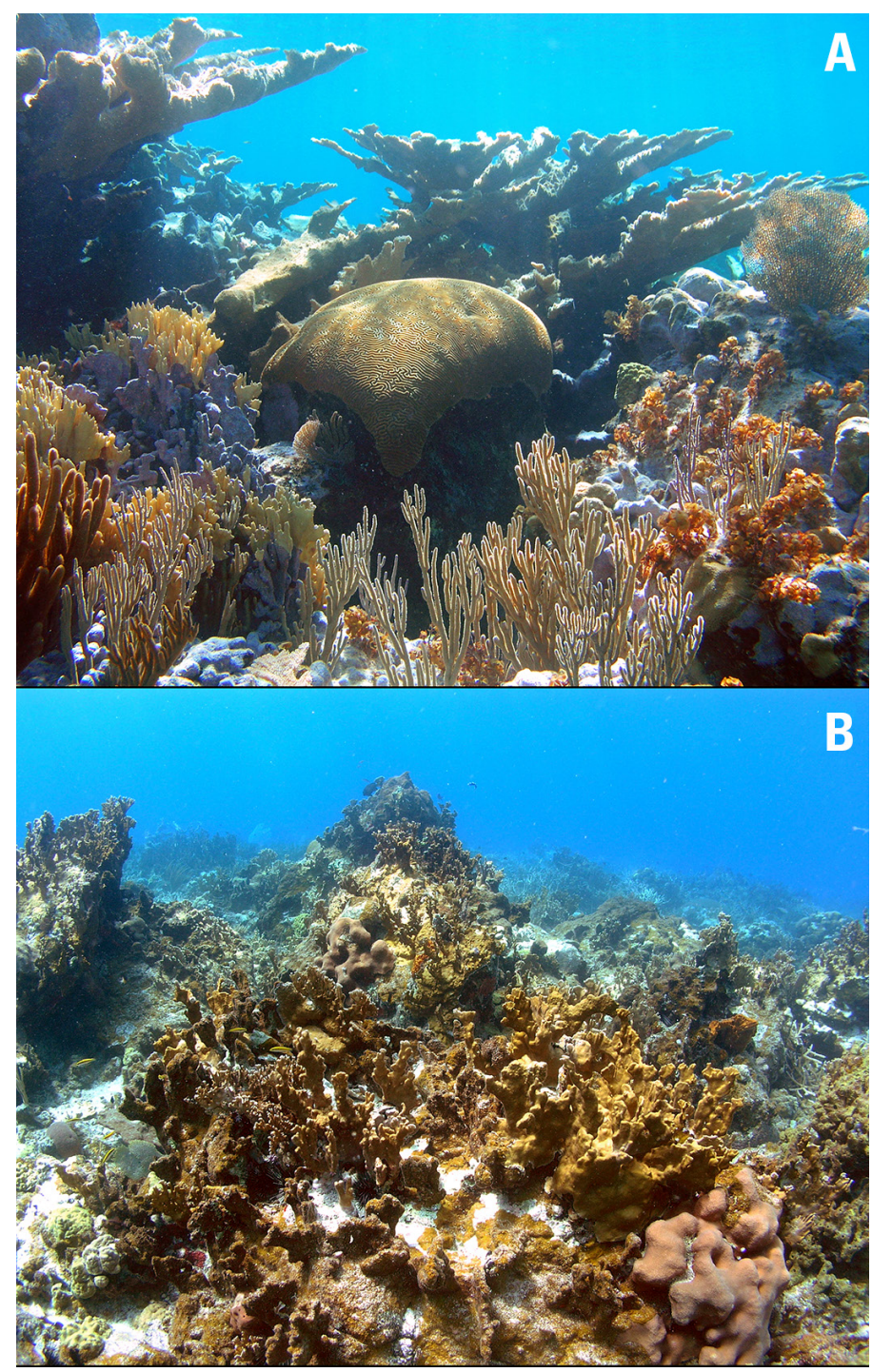

Figure 1. Coral reef habitat $(A)$ dominated by reef-building species including Elkhorn and Brain Coral (Great Exuma, Bahamas) and (B) covered with non-framework building species like Fire Coral and fleshy seaweed (St. Thomas, U.S. Virgin Islands).

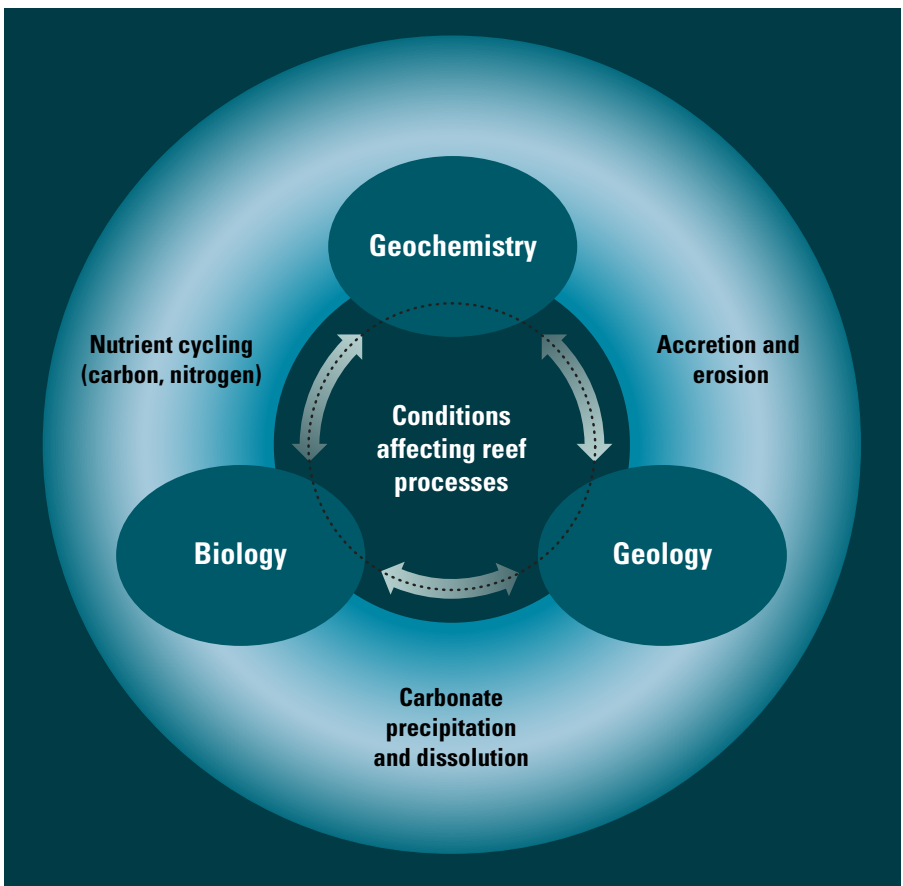

Figure 2. Three scientific disciplines are combined to document and quantify reef processes that determine whether a coral reef grows or crumbles apart.

\section{Research Focus}

Coral reefs are complex ecosystems where environmental and biological factors are constantly interacting, creating a heterogeneous and ever-changing landscape across multiple spatial and temporal scales. The U.S. Geological Survey (USGS) Coral Reef Ecosystem Studies (CREST) project combines expertise in three areas (geology, biology, and geochemistry) to characterize reef processes including calcification, reef accretion (growth) and erosion, sand production and transport, and habitat construction (fig. 2). We take a "reefscape" approach to address several key issues related to the current status, declining health, and resilience of shallow-water reef communities in the U.S. Caribbean, Gulf of Mexico, and Florida Keys.

The interconnecting components of the CREST project represent multiple disciplines working together to answer two fundamental questions: (1) What are the drivers that determine rates of carbonate production (fig. 3, left), erosion, transport, and reef construction, and (2) Will reefs cease to accrete in the near future in the context of ocean warming, ocean acidification, and (or) compromised water quality? We also explore the seasonal, spatial (vertical and horizontal), and retrospective (historical and geological) heterogeneity in the reef processes we are investigating through coordinated field expeditions (fig. 3, center). For maximum comparative value, we are examining reef processes on both a senescent 


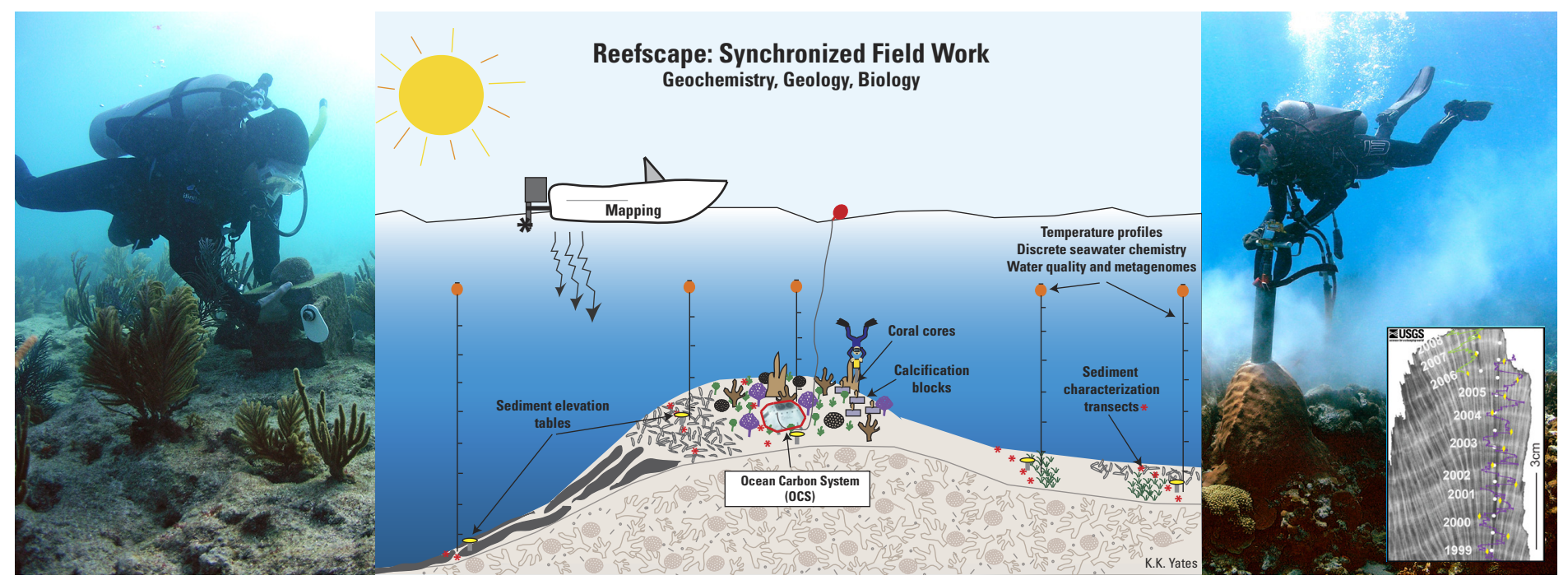

Figure 3. Left: A calcification monitoring station at Molasses Reef Sanctuary Preservation Area in the Florida Keys National Marine Sanctuary. In 2009, a network of such stations was set up at five outer-bank reef sites from Miami to the Dry Tortugas to quantify calcification rates by corals and other calcifiers and to determine the factors that control carbonate production. Center: Diagram showing CREST's reefscape approach to assessing and quantifying processes on degraded as well as healthier reefs. The Ocean Carbon System (OCS) is a suite of instruments that quantifies variables related to ocean acidification and the water's conduciveness to supporting calcification or carbonate dissolution. Right: A USGS diver drills a live coral head in the U.S. Virgin Islands to obtain samples for reconstructing past sea-surface temperatures (SST), using geochemical proxies. Inset photograph shows an x-ray of a coral slab with overlain geochemical data that display the annual cycles in SST.

reef (Crocker) in the Florida Keys, and a healthier reef (Pulaski Shoal) in the Dry Tortugas. In tandem, we are retrospectively examining these processes and the environmental drivers that control them by looking at records from live coral and fossil reefs, reconstructing sea-surface temperatures by using geochemical proxies (fig. 3, right), and quantifying rates of reef growth during the Holocene epoch (fig. 4).

\section{Relevance to Resource Management}

The CREST project is a long-term research effort involving a blend of process studies and monitoring activities relevant to understanding the resilience of shallow-water reef environments. We work closely with three National Parks (N.P.): Dry Tortugas N.P., Virgin Islands N.P., and Biscayne N.P., as well as the Florida Keys National Marine Sanctuary (FKNMS). Deliverables from CREST include:

- $\quad$ Products and expert advice provided to resource managers in Department of Interior agencies, States, territories, and other Federal agencies regarding coral-reef resilience and functioning

- Advancement in the ability to forecast changes to coralreef environments in response to a changing climate

- Risk assessments to quantify the probability of ecosystemservice loss due to coral-reef degradation

Information and products resulting from our work (see http://coastal.er.usgs.gov/crest/) will help guide policies and best management practices to preserve and restore U.S. coralreef resources. Documenting the natural variability in these processes will afford us a much better chance of detecting and quantifying potential impacts of global climate change and altered water quality on reef accretion. The processes that determine whether a reef is building or crumbling apart is fundamental to the ability of this critical ecosystem to deliver the services that coastal communities depend upon.

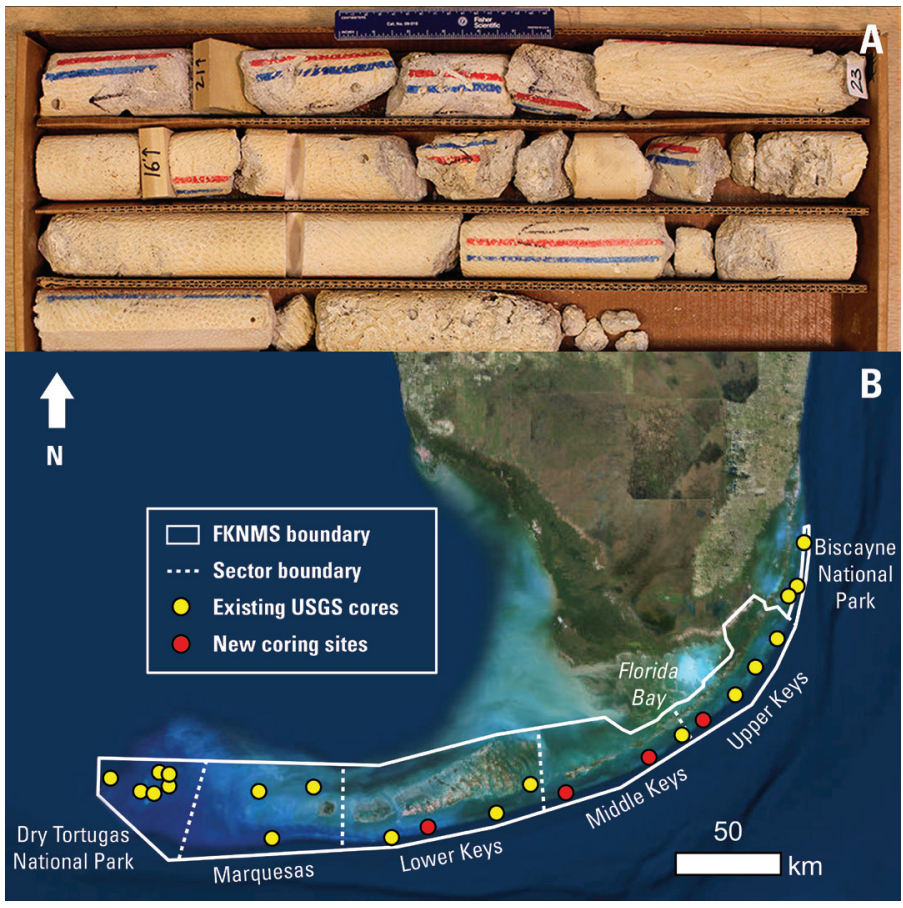

Figure 4. Investigating reef-accretion (growth) rates throughout the Holocene epoch (approximately the last 12,000 years) involves drilling fossil reefs to obtain $(A)$ core samples that can be dated using various techniques. The USGS St. Petersburg Coastal and Marine Science Center has an extensive archive of reef cores that have been collected over the past five decades, many of which are being used in (B) a current study to quantify and map reef growth throughout the Florida Keys.

\begin{tabular}{|lll|}
\hline Contact Information: & \\
Ilsa B. Kuffner & ikuffner@usgs.gov & $727-502-8048$ \\
Kimberly K. Yates & kyates@usgs.gov & $727-502-8059$ \\
David G. Zawada & dzawada@usgs.gov & $727-502-8132$ \\
Julie N. Richey & jrichey@usgs.gov & $727-502-8123$ \\
Christina A. Kellogg & ckellogg@usgs.gov & $727-502-8128$ \\
Lauren T. Toth & Itoth@usgs.gov & $727-502-8029$ \\
St. Petersburg Coastal and Marine Science Center & \\
600 4th Street S, St. Petersburg, FL 33701 & \\
\hline
\end{tabular}

